\title{
Síndrome compartimental
}

em paciente submetido à cirurgia

\section{urológica videolaparoscópica}

\author{
CET-SBA, Departamento de Anestesiologia da Faculdade de Medicina \\ da Universidade Estadual Paulista, Botucatu, São Paulo
}

INTRRDUÇÃa

A síndrome compartimental nos membros inferiores é rara, porém é uma complicação potencialmente devastadora, decorrente da posição de litotomia durante o intra-operatório.

RELATI DO CASD

Paciente do sexo feminino, 51 anos, $73 \mathrm{~kg}, 1,56 \mathrm{~m}$, P1 (antigo ASA I) por transtorno depressivo, ex-tabagista, submetida à cirurgia para correção de fístula vésico-vaginal por via videolaparoscópica. Monitorização com cardioscópio, oxímetro de pulso e monitor de pressão não-invasiva. Indução com sufentanil, propofol e rocurônio. Intubação orotraqueal realizada sem intercorrências. Instalada capnografia. A paciente foi mantida com isoflurano, óxido nitroso e sufentanil contínuos e colocada em posição de litotomia (Lloyd Davies) e Trendelenburg. Foi insuflado o pneumoperitôneo e iniciada a cirurgia após 1 h e 15 min da intubação. Intra-operatório prolongado devido a dificuldades cirúrgicas, não ocorrendo em nenhum momento instabilidade hemodinâmica ou respiratória. Permaneceu na mesma posição por 5 horas. Retirada da posição ao final da cirurgia e levada à SRPA ainda intubada, hemodinamicamente estável. Depois de 15 minutos, desintubação realizada sem intercorrências. Logo após, iniciou-se queixa de dor de grande intensidade na perna esquerda. Ao exame, observou-se aumento do volume da mesma, com tensão importante da musculatura e com diminuição da perfusão e dos pulsos distais. Realizou-se o diagnóstico de síndrome compartimental e optou-se pela realização de fasciotomia. A paciente evoluiu no pós-operatório imediato com quadro de taquicardia e dispnéia, levantando-se a hipótese de tromboembolismo pulmonar. Realizados no primeiro pós-operatório dopler venoso e cintilografia de ventilação-perfusão, sendo descartadas as hipóteses de TEP e TVP. Submetida no nono pós-operatório a enxerto dermoepidérmico. Alta no $12^{\circ}$ pós-operatório.

\section{DISCUSSÃロ}

Alguns cuidados devem ser adotados para se diminuir o risco da síndrome compartimental em pacientes submetidos à cirurgia de longa duração na posição de litotomia. Esses pacientes também devcm ser rigorosamente acompanhados na SRPA para diagnóstico precoce dessa complicação, visando diminuir sua morbimortalidade.

REFERÊNCIA

Turnbull D, Mills GH. Compartment syndrome associated with the Lloyd Davies position: three case reports and review of the literature. Anaesth. 2001;56(10):980-7.

\footnotetext{
Endereço para correspondência:

Thiago Coletti Remond Manfrin

Distrito de Rubião Junior, $s / n$ ㅇ

Botucatu (SP) - CEP 18618-970

Tel. (+55 14) 3811 1-6222

Fax (+55 14) 3815-9015

E-mail: anestesi@fmb.unesp.br
} 